\title{
Maternal and perinatal adverse outcomes in women with pre-eclampsia cared for at facility-level in South Africa: a prospective cohort study
}

\author{
Hannah L Nathan ${ }^{1}$, Paul T \\ Seed $^{1}$, Natasha L Hezelgrave ${ }^{1}$, \\ Annemarie De Greeff ${ }^{1}$, Elodie \\ Lawley ${ }^{1}$, Frances Conti- \\ Ramsden ${ }^{1}$, John Anthony², \\ Wilhelm Steyn ${ }^{3}$, David R Hall ${ }^{3}$, \\ Lucy C Chappell ${ }^{1}$, Andrew H \\ Shennan ${ }^{1}$ \\ ${ }^{1}$ Department of Women and \\ Children's Health, King's College \\ London, London, UK \\ ${ }^{2}$ Department of Obstetrics and \\ Gynaecology, University of Cape Town, \\ Cape Town, South Africa \\ ${ }^{3}$ Department of Obstetrics and \\ Gynaecology, Stellenbosch University, \\ Cape Town, South Africa
}

\begin{abstract}
Background Hypertensive disorders of pregnancy contribute to $14 \%$ of all maternal deaths, the majority of which occur in low- and middle-income countries. The aim of the study was to describe the maternal and perinatal clinical outcomes of women with pre-eclampsia living in middle- and low-income countries.
\end{abstract}

Methods The study was a prospective observational study of women with pre-eclampsia ( $n=1547,42$ twin pregnancies) at three South African tertiary facilities. Using stepwise logistic regression model area under the receiver operating characteristic curve (AUROC) values, the association between maternal baseline and admission characteristics and risk of adverse outcomes was evaluated. Main outcome measures were eclampsia, kidney injury and perinatal death.

Results In 1547 women with pre-eclampsia, 16 (1\%) died, 147 (9.5\%) had eclampsia, four (0.3\%) had a stroke and 272 (17.6\%) had kidney injury. Of the 1589 births, there were 332 (21.0\%) perinatal deaths; of these, 281 (84.5\%) were stillbirths. Of 1308 live births, 913 (70.0\%) delivered $<37$ completed weeks and $544(41.7 \%)$ delivered $<34$ weeks' gestation. Young maternal age (AUROC $=0.76,95 \%$ confidence interval $(\mathrm{CI})=0.71$ 0.80) and low Body Mass Index BMI (AUROC 0.65, 95\% CI=0.59-0.69) were significant predictors of eclampsia. Highest systolic blood pressure had the strongest association with kidney injury, (AUROC $=0.64,95 \%$ $\mathrm{CI}=0.60-0.68)$. Early gestation at admission was most strongly associated with perinatal death $(\mathrm{AUROC}=0.81,95 \% \mathrm{CI}=0.77-0.84)$.

Conclusions The incidence of pre-eclampsia complications, perinatal death and preterm delivery in women referred to tertiary care in South Africa was much higher than reported in other low- and middle-income studies and despite access to tertiary care interventions. Teenage mothers and those with low BMI were at highest risk of eclampsia. This information could be used to inform guidelines, the research agenda and policy.

Approximately 800 women die every day from problems related to pregnancy and childbirth [1], with hypertensive disorders of pregnancy causing 14\% of all maternal deaths and pre-eclampsia contributing to 500000 perinatal deaths annually [2,3]. In South Africa, with provision of high-level tertiary care, hypertensive disorders of pregnancy are the second leading cause of maternal death $[4,5]$.

Over the last century, maternal mortality rates in high-income countries have steadily declined. Now, almost all maternal deaths occur in low- and middle-in- 
come countries (LMICs) [6]. In 2015, the lifetime risk of maternal death in high-income countries was 1 death per 6000 pregnant women compared to 1 death in 36 in sub-Saharan Africa [7]. In high-income countries, maternal mortality from pre-eclampsia declined most dramatically between 1940 and 1970, with a $90 \%$ reduction in eclampsia. This is largely due to improved antenatal care and better access to timely delivery [8]. In LMIC settings women continue to die from preventable complications of pre-eclampsia. It is unclear whether routine pregnancy care or emergency obstetric care should be primarily targeted as strategies for improving outcomes.

This study aimed to describe the maternal and perinatal clinical outcomes of pre-eclamptic women treated in tertiary facilities in South Africa, a middle-income country setting where appropriate medical care is available. The study also aimed to evaluate the association between maternal baseline and admission characteristics and the risk of four severe clinical outcomes.

\section{METHODS}

This prospective observational cohort study was undertaken between January 2015 and May 2016 at three state tertiary level maternity units in South Africa (Groote Schuur, Tygerberg and Kimberley Hospitals). Women with a clinical diagnosis of pre-eclampsia determined by the woman's health care provider during their admission (either antepartum or postpartum) were included in the study. There were no exclusion criteria.

Clinicians managed women according to local practices. Blood pressure (BP) measurements were taken using the Microlife CRADLE Vital Signs Alert (VSA), a BP device validated for use in pregnancy, including pre-eclampsia [9]. Almost all existing BP devices were replaced with the VSA in the three maternity units; BP monitoring systems within anaesthetic and recovery machines could not be replaced.

Data were extracted through patient notes reviewed by a local researcher at each site. Data quality checks were undertaken on the database by a subsequent researcher and any disagreement was resolved by a medically trained adjudicator. Women with missing data were included but not analysed for the variable for which the data were missing.

Frequencies were used to describe maternal baseline and admission characteristics and to describe the proportion of women affected by maternal, perinatal and process measure adverse clinical outcomes. At the time of designing the study, a core outcome set for pre-eclampsia or hypertension in pregnancy did not exist. The principal clinical outcomes were pre-specified in the study protocol as maternal death, eclampsia, stroke, kidney injury and perinatal death. Secondary clinical outcomes were process measures (maternal magnesium sulphate administration, maternal Critical Care Unit (CCU) admission) and perinatal outcomes (stillbirth, early and late neonatal death, delivery at $<34$ weeks, delivery at $<37$ weeks). Kidney injury was defined as highest creatinine during admission $\geq 90 \mu \mathrm{mol} / \mathrm{L}$. It was not possible to distinguish between acute kidney injury (as a consequence of pre-eclampsia) and chronic renal disease, because baseline creatinine levels were not known. Early neonatal death was defined as death in the first 7 days of life; late neonatal death was defined as death between 8 and 28 days of life. Perinatal death was defined as including stillbirth, early neonatal and late neonatal death ie, extended perinatal death [10]. Critical Care Unit admission was defined as admission to a critical care area providing at least additional monitoring and interventions [11]. Eclampsia and stroke were recorded if they occurred prior to or during admission. Maternal death was recorded if it occurred during admission only. Stillbirth may have occurred prior to admission but was only recorded when identified during admission.

For objective clinical endpoints (maternal death, eclampsia, stroke, kidney injury and perinatal death), analysis using logistic regression models for correlation between baseline and admission characteristics and these outcomes was performed, using AUROC values and 95\% confidence intervals (CI). The aim of the logistic regression models was to explore which variables were most strongly associated with outcomes, rather than to create a clinical prediction model.

The study was approved by the Stellenbosch University Ethics Committee (N14/06068), University of Cape Town Ethics Committees (410/2014) and the University of the Free State Ethics Committee (230408011). Local ethics committees at two of the three sites required individual informed written consent to be obtained before the woman was enrolled in the study (or waiver of consent was granted if the woman was unconscious). Institutional level agreement for the study was given at the third site. The study was funded by The Bill and Melinda Gates Foundation (Grant ID: OPP1086183). The funders were not 
involved in conducting the research or writing the paper. Patients were not involved in the designing or analysis of the study.

As an observational study, a formal power calculation was not undertaken. Intended sample sizes are outlined in the study protocol. Three large units with a high prevalence of hypertension were selected to obtain a meaningful sample to evaluate clinical associations. It was considered that the high numbers of adverse outcomes anticipated would allow accurate determination of clinically important associations. Statistical analysis was performed in the statistical package Stata (version 11.2), College Station, TX. The study is reported in accordance with STrengthening the Reporting of OBservational studies in Epidemiology (STROBE) guidelines.

\section{RESULTS}

A total of 1547 women with a clinical diagnosis of pre-eclampsia were eligible, consented and were included in the analysis, including 42 twin pregnancies (Figure 1). Comparison with expected monthly numbers of cases in these units showed that a high majority of women were recruited but formal documentation of women who declined was not made. Participant characteristics are shown in Table 1. The BMI in this cohort of women was high (mean BMI $30.4 \mathrm{~kg} / \mathrm{m}^{2}$; SD 7.73) and the majority were multiparous (63.5\%). The mean highest BP during admission was 172/104 mm Hg and $43 \%$ of the highest BPs during admission occurred in the postpartum period (Table 1). 89.3\% of women had one plus or more dipstick proteinuria on admission; the remaining women fulfilled other pre-eclampsia diagnostic criteria or developed proteinuria whilst an inpatient. Mean gestational age at delivery was 33.4 weeks (SD 4.7); $87.8 \%$ of women had an iatrogenic onset of labour (clinician-indicated) and $69.7 \%$ of deliveries were by Caesarean section.

In this population of women with pre-eclampsia, 16 (1\%) women died during their admission. Eclampsia occurred in 147 (9.5\%) women and identified stroke occurred in 4 (0.3\%) women. Of the 16 women who died, ten also had eclampsia. $7 \%$ of those with eclampsia died, compared to $0.4 \%$ of those without eclampsia (relative risk 15.9; 95\% CI=5.9-43.1). Three of the four women with stroke also had eclampsia and subsequently died. Most women received magnesium sulphate (86.9\%). 17.6\% of women had kidney injury and 3\% of those with kidney injury died, compared to $0.5 \%$ of those with normal creatinine (relative risk 6.2; 95\% CI=2.2-17.8). Of 1589 births, 332 (21.0\%) had a perinatal death; of these, 281 (84.5\%) were stillbirths and 51 (15.4\%) were neonatal deaths. Of 1308 live births, 913 (70.0\%) were born preterm prior to 37 completed weeks of gestation, and 544 (41.7\%) were born before 34 weeks' gestation (Table 2).

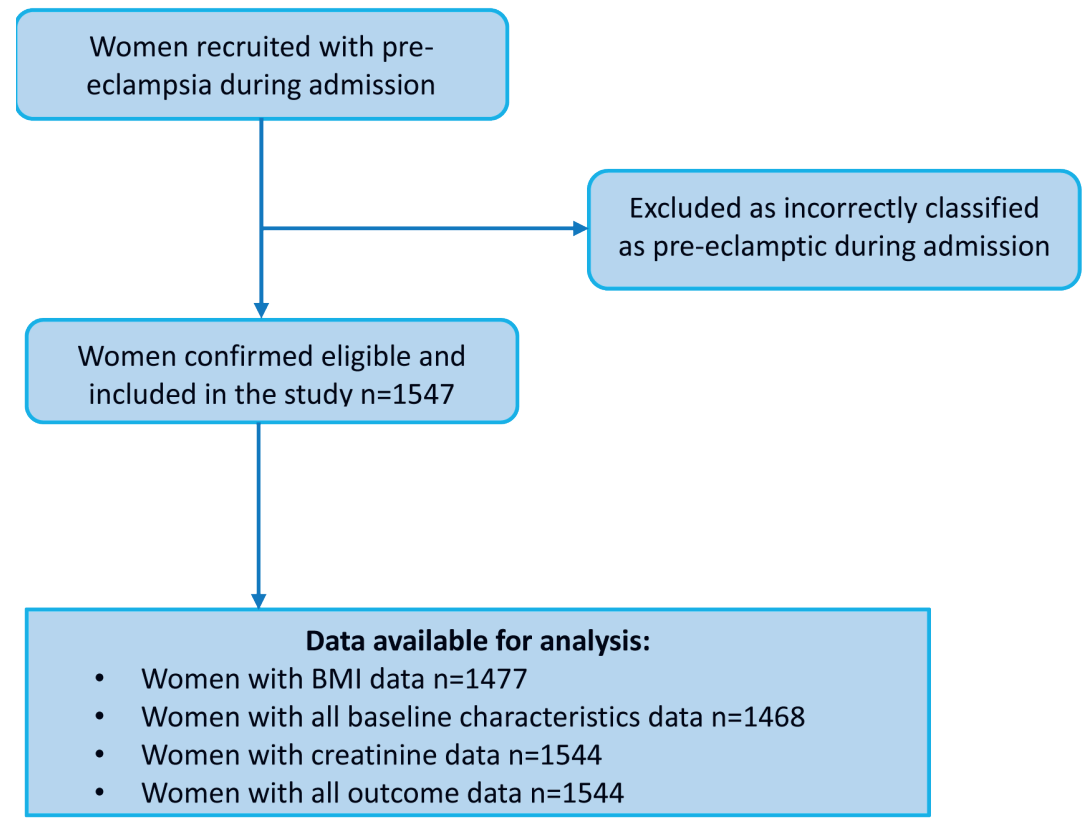

Figure 1. Flow diagram of participants. 
Table 1. Mean \pm standard deviation or $\mathrm{n}$ (percentage) of demographic, admission and delivery characteristics. BMI body mass index.

\begin{tabular}{|c|c|c|c|c|}
\hline & All sIIES & $\begin{array}{l}\text { Groote SchuUR } \\
\text { Hospital }\end{array}$ & KIMBeriey Hospital & Tyeerberg Hospital \\
\hline Number of women & 1547 & $770(49.8)$ & $167(10.8)$ & $610(39.4)$ \\
\hline \multicolumn{5}{|l|}{ Demographics: } \\
\hline Age at delivery, year & $27.6 \pm 6.2$ & $28.0 \pm 6.0$ & $28.3 \pm 7.2$ & $27.0 \pm 6.2$ \\
\hline Body mass index, $\mathrm{kg} / \mathrm{m}^{2}$ & $30.4 \pm 7.73$ & $31.0 \pm 8.3$ & $31.9 \pm 8.3$ & $29.2 \pm 6.7$ \\
\hline Multiparous & $983(63.5)$ & $514(66.8)$ & $117(70.1)$ & $352(57.7)$ \\
\hline \multicolumn{5}{|l|}{ Admission: } \\
\hline Gestation on admission, weeks & $32.8 \pm 4.9$ & $32.0 \pm 4.8$ & $33.9 \pm 4.7$ & $33.5 \pm 4.9$ \\
\hline Systolic BP (mmHg) & $150 \pm 20.6$ & $150 \pm 22.3$ & $147 \pm 20.0$ & $150 \pm 18.2$ \\
\hline Diastolic BP (mmHg) & $97 \pm 15.4$ & $98 \pm 15.6$ & $92 \pm 16.9$ & $97 \pm 14.3$ \\
\hline Negative/Trace dipstick proteinuria & $165(10.7)$ & $93(12.1)$ & $69(42.6)$ & $3(0.5)$ \\
\hline+1 & $196(12.7)$ & $134(17.4)$ & $15(9.3)$ & $47(7.7)$ \\
\hline+2 & $578(37.5)$ & $245(31.9)$ & $32(19.8)$ & $301(49.3)$ \\
\hline+3 & $601(39.0)$ & $296(38.5)$ & $46(28.4)$ & $259(42.5)$ \\
\hline 24-h urine completed & $379(24.5)$ & $170(22.1)$ & $23(15.2)$ & $186(30.8)$ \\
\hline 24-h proteinuria $(\mathrm{g} / 24 \mathrm{~h})$ & $1.8 \pm 2.3$ & $1.7 \pm 2.3$ & $1.4 \pm 2.1$ & $1.92 \pm 2.3$ \\
\hline \multicolumn{5}{|l|}{ Delivery: } \\
\hline Admission to delivery, days & $4.1 \pm 7.3$ & $5.1 \pm 8.1$ & $3.9 \pm 9.6$ & $3.0 \pm 4.8$ \\
\hline Gestation at delivery, weeks & $33.4 \pm 4.7$ & $32.8 \pm 4.5$ & $34.5 \pm 4.4$ & $33.9 \pm 4.9$ \\
\hline Clinician-indicated (iatrogenic) delivery & $1357(87.8)$ & $636(82.6)$ & $147(88.6)$ & $574(94.3)$ \\
\hline Caesarean section (pre-labour and emergency) & $1060(69.7)$ & $549(71.3)$ & $115(69.3)$ & $417(68.5)$ \\
\hline \multicolumn{5}{|l|}{ Highest BP (mmHg): } \\
\hline Systolic BP & $172 \pm 16.9$ & $174 \pm 17.9$ & $171 \pm 16.1$ & $170 \pm 15.7$ \\
\hline Diastolic BP & $104 \pm 14.60$ & $106 \pm 15.7$ & $102 \pm 17.1$ & $103 \pm 12.2$ \\
\hline Highest SBP taken postpartum & $658(42.9)$ & $333(43.3)$ & $95(57.6)$ & $230(38.2)$ \\
\hline $\begin{array}{l}\text { Time from highest (antenatal/ intrapartum) } \\
\text { systolic BP to delivery, days }(\mathrm{n}=876)\end{array}$ & $3.0 \pm 5.9$ & $3.8 \pm 6.9$ & $2.7 \pm 6.36$ & $2.1 \pm 4.0$ \\
\hline $\begin{array}{l}\text { Time from delivery to highest systolic BP } \\
\text { (postnatal), days }(\mathrm{n}=658)\end{array}$ & $1.6 \pm 6.1$ & $1.2 \pm 1.4$ & $2.3 \pm 2.3$ & $2.3 \pm 1.8$ \\
\hline
\end{tabular}

Table 2. Mean \pm standard deviation or $n$ (percentage) of principal maternal, secondary maternal, principal perinatal, secondary perinatal and process measure outcomes

\begin{tabular}{|c|c|c|c|c|}
\hline & All SIIES & $\begin{array}{c}\text { Groote SchuUr } \\
\text { Hospital }\end{array}$ & KImBeriey Hospital & Tyeerberg Hospital \\
\hline Number of women & 1547 & $770(49.8)$ & $167(10.8)$ & $610(39.4)$ \\
\hline \multicolumn{5}{|l|}{ Principal outcomes } \\
\hline \multicolumn{5}{|l|}{ Maternal outcomes: } \\
\hline Maternal death & $16(1.0)$ & $3(0.4)$ & $6(3.6)$ & $7(1.1)$ \\
\hline Eclampsia & $147(9.5)$ & $71(9.2)$ & $16(9.6)$ & $60(9.8)$ \\
\hline Stroke & $4(0.3)$ & $2(0.3)$ & $0(0)$ & $2(0.3)$ \\
\hline Highest creatinine during admission $(\mu \mathrm{mol} / \mathrm{L})$ & $79.6 \pm 78.8$ & $86.0 \pm 76.4$ & $84.96 \pm 116.40$ & $70.1 \pm 69.9$ \\
\hline Kidney injury $(\mathrm{n}=1544)$ & $272(17.6)$ & $174(22.6)$ & $26(15.9)$ & $72(11.8)$ \\
\hline PERINATAL DEATH & $332(21.0)$ & $188(23.6)$ & $80(15.1)$ & $118(18.9)$ \\
\hline \multicolumn{5}{|l|}{ Secondary outcomes } \\
\hline \multicolumn{5}{|l|}{ Process measures: } \\
\hline Maternal magnesium sulphate administration & $1345(86.9)$ & $686(89.1)$ & $120(71.9)$ & $539(88.4)$ \\
\hline Maternal Critical Care Unit admission & $453(29.3)$ & $105(13.6)$ & $114(68.3)$ & $234(38.4)$ \\
\hline Total number of infants & 1589 & 793 & 172 & 624 \\
\hline \multicolumn{5}{|l|}{ Perinatal outcomes: } \\
\hline Stillbirth & $281(17.7)$ & $162(20.4)$ & $16(9.3)$ & $103(16.5)$ \\
\hline Early neonatal death & $39(2.5)$ & $21(2.6)$ & $6(3.5)$ & $12(1.9)$ \\
\hline Late neonatal death & $12(0.8)$ & $5(0.6)$ & $4(2.3)$ & $3(0.5)$ \\
\hline Preterm birth $<37$ weeks & $913(70.0)$ & $491(78.1)$ & $99(63.5)$ & $323(62.1)$ \\
\hline Preterm birth $<34$ weeks & $544(41.7)$ & $303(48.2)$ & $52(33.3)$ & $189(36.3)$ \\
\hline
\end{tabular}


Using stepwise logistic regression modelling, the association between baseline and admission characteristics and the principal clinical outcomes was evaluated, including eclampsia, kidney injury and perinatal death (Table 3). Due to small numbers, maternal death and stroke were excluded from this analysis.

Young maternal age was the strongest single predictor of eclampsia (AUROC $=0.76,95 \% \mathrm{CI}=0.71-0.80$ ); women younger than 20 years had a 30\% risk of eclampsia whilst women of 30 years or older had a 3.5\% risk of eclampsia. The association between young maternal age and eclampsia occurred despite mean admission SBP and highest SBP during admission significantly increasing with advancing maternal age. The unadjusted odds ratio for eclampsia in women younger than 20 years, compared to those aged 20-29 years, was 4.52 (95\% CI=3.02-6.76). Following adjustment for admission and highest $\mathrm{BP}$, the odds ratio was 5.04 ( $95 \% \mathrm{CI}=3.34-7.61$ ). Therefore, $\mathrm{BP}$ works against the association between age and eclampsia, but only weakly. There was a $40 \%$ risk of eclampsia in women with BMI less than $18.5 \mathrm{~kg} / \mathrm{m}^{2}$; in women with $\mathrm{BMI} \geq 35 \mathrm{~kg} / \mathrm{m}^{2}$, the risk of eclampsia was $5.6 \%$ (AUROC $=0.64,95 \% \mathrm{CI}=0.59-0.69$ ). BP variables were not significant predictors on their own for risk of eclampsia.

For eclampsia, the model including maternal age, BMI, gestational age at admission, highest SBP, and admission dipstick proteinuria, gave an AUROC value of 0.79 (95\% CI=0.75-0.83). Maternal age and nulliparity conveyed similar risk of eclampsia as measured by changes in the log likelihood, with young women and nulliparous women being at higher risk; therefore, only young maternal age (the stronger of the two predictors) was necessary in the model. Although BP variables were not significantly associated with eclampsia individually, highest SBP was included in the model as it was significant after adjustment.

For kidney injury, highest SBP had the strongest association (AUROC $=0.64,95 \% \mathrm{CI}=0.60-0.68$ ). For women with a highest SBP $\geq 200 \mathrm{~mm} \mathrm{Hg}, 40 \%$ had kidney injury. When a change in SBP (from admission to highest SBP) was compared to highest SBP alone, highest SBP performed better than change in SBP. For prediction of kidney injury, a model including gestational age at admission, admission SBP and DBP, highest SBP, and admission dipstick proteinuria gave an AUROC value of $0.68(\mathrm{CI}=0.64-0.72)$.

Gestation at admission was the most strongly associated variable with perinatal death (AUROC $=0.81$, $95 \% \mathrm{CI}=0.77-0.84$ ), with early gestation strongly associated with perinatal death. Between 26 and 27 completed weeks of pregnancy, risk of perinatal death was 50\%; from 32 weeks' gestation, risk of perinatal death was approximately $\leq 10 \%$. All BP variables were statistically not significantly associated with perinatal death.

For perinatal death, the model, including gestational age at admission, admission SBP and admission dipstick proteinuria, gave an AUROC value of 0.81 (0.79-0.84). Again, although BP variables were not statistically significantly associated with perinatal death as individual variables, highest SBP was included in the model as it was significant after adjustment.

Table 3. Stepwise logistic regression model AUROC values and 95\% confidence intervals for the association between baseline and admission characteristics and the three principle outcomes (eclampsia, kidney injury and perinatal death)*

\begin{tabular}{|c|c|c|c|c|c|c|}
\hline \multirow{3}{*}{$\begin{array}{l}\text { PREDICTORS } \\
\text { Total number of women }\end{array}$} & \multicolumn{2}{|c|}{ ECLAMPSIA } & \multicolumn{2}{|c|}{ KIDNEY InJURY } & \multicolumn{2}{|c|}{ Perinatal death } \\
\hline & \multicolumn{2}{|c|}{1460} & \multicolumn{2}{|c|}{1459} & \multicolumn{2}{|c|}{1500} \\
\hline & AUROC & $95 \% \mathrm{CI}$ & AUROC & $95 \% \mathrm{CI}$ & AUROC & $95 \% \mathrm{CI}$ \\
\hline Prediction model & 0.79 & $0.75,0.83$ & 0.68 & $0.64,0.72$ & 0.81 & $0.79,0.84$ \\
\hline Advanced maternal age & $0.76 \downarrow$ & $0.71,0.80$ & 0.52 & $0.48,0.56$ & 0.46 & $0.43,0.50$ \\
\hline High Body mass index & $0.64 \downarrow$ & $0.59,0.69$ & 0.46 & $0.42,0.50$ & 0.50 & $0.46,0.54$ \\
\hline Multiparity & $0.67 \downarrow$ & $0.63,0.71$ & 0.53 & $0.50,0.56$ & 0.56 & $0.53,0.58$ \\
\hline Low gestation at admission & 0.59 & $0.54,0.64$ & 0.58 & $0.54,0.62$ & 0.81 & $0.77,0.84$ \\
\hline High admission systolic BP & 0.52 & $0.47,0.58$ & 0.55 & $0.51,0.59$ & 0.52 & $0.49,0.56$ \\
\hline High admission diastolic BP & 0.53 & $0.47,0.58$ & 0.57 & $0.53,0.62$ & 0.51 & $0.47,0.55$ \\
\hline High highest systolic BP & 0.54 & $0.49,0.59$ & 0.64 & $0.60,0.68$ & 0.46 & $0.42,0.50$ \\
\hline High diastolic BP at highest systolic BP & 0.51 & $0.46,0.57$ & 0.59 & $0.55,0.63$ & 0.48 & $0.44,0.52$ \\
\hline High admission dipstick proteinuria & 0.59 & $0.54,0.64$ & 0.59 & $0.56,0.63$ & 0.54 & $0.51,0.58$ \\
\hline
\end{tabular}

CI - confidence interval, AUROC - area under the receiver operating characteristic curve

* Most important characteristic for each outcome shown in bold. Direction of association as stated in first column, unless an arrow present $(\downarrow)$, indicating association in opposite direction 


\section{DISCUSSION}

\section{Main findings}

In this South African cohort with pre-eclampsia managed in tertiary facilities, severe hypertension and pre-eclampsia complications were common. Young maternal age was strongly associated with risk of eclampsia, highest SBP was associated with kidney injury and early gestation at admission was associated with perinatal death.

\section{Strengths and limitations}

This large, multi-centre, prospective study of women with pre-eclampsia managed in South African tertiary facilities explored the incidence of complications and their association with baseline and admission characteristics. Although women in secondary level facilities may not have severe disease, this cohort is representative of referral facilities that manage women with mild to severe pre-eclampsia.

The vital signs included in analysis were taken at and following admission to tertiary care, with many having already received treatment. It was not feasible to collect accurate temporal data on antihypertensive and magnesium sulphate use and adverse outcomes due to minimal documentation. Therefore, assessing for effects of intervention and determining the temporal association between interventions and outcomes, including eclampsia and stillbirth, was not possible.

Severe hypertension and pre-eclampsia complications were common, despite access to antihypertensive therapy, magnesium sulphate administration and critical care. Despite referral to tertiary-level care, the eclampsia incidence in our cohort (9.5\%) was much higher than the incidence of eclampsia in the MAGPIE trial low-income country pre-eclampsia cohort (2.3\%) [12]. The MAGPIE trial eclampsia incidence may have been underestimated as only hospital data were used, excluding women giving birth outside facilities. In our setting, most births occur at facility-level and our incidence may be more reflective of the true incidence of eclampsia in South Africa. However, in our study it was not possible to distinguish between eclampsia that occurred prior to tertiary care and eclampsia that occurred whilst receiving tertiary care, due to limitations with patient notes documentation. The eclampsia incidence may appear higher than expected for women receiving adequate care because the eclampsia may have occurred prior to that care.

Stroke occurred in $0.3 \%$ of women in this cohort, in association with a high incidence of severe systolic hypertension. The association between systolic hypertension and pre-eclampsia-related stroke was shown in a small cohort study of 28 women with pre-eclampsia-related stroke, with $95.8 \%$ of women with BP measurements taken immediately prior to the stroke having a systolic $\mathrm{BP} \geq 160 \mathrm{mmHg}$ [13]. This study has been criticised due to small sample size, lack of statistical analysis confirming the independent association of SBP and potentially biased case ascertainment [14]. However, the low incidence of stroke in our cohort may reflect an underestimation of stroke incidence, with stroke going unrecognised unless severe, categorised as eclampsia or missed when occurring postnatally away from facility. Conversely, it may be the true incidence and demonstrate good management of severe systolic hypertension once in tertiary care.

Stillbirth was more common in our cohort (17.7\%) than the recent WHO multi-country survey's stillbirth rate of $6.36 \%$ in women with pre-eclampsia [15]. The high stillbirth rate in our cohort may reflect inadequate primary and secondary antenatal care. Most livebirths within our cohort were preterm, iatrogenic and delivered by Caesarean section. This may reflect appropriate obstetric care in response to pre-eclampsia complications and good neonatal facilities once receiving tertiary care. There were relatively few neonatal deaths, suggesting prematurity was not a major contributor to perinatal mortality in this setting.

Current literature suggests advanced maternal age, obesity and black ethnicity are associated with risk of pre-eclampsia [16-22]. In our cohort, despite BP increasing with advancing maternal age, younger women were at higher risk of eclampsia. Similar associations were shown in the WHO multi-country survey; adolescents of $<17$ years were more likely to develop eclampsia (adjusted odds ratio 1.73; 95\% $\mathrm{CI}=1.23-2.43$ ), despite no association between young age and pre-eclampsia [15]. Retrospective studies of women with eclampsia in Nigeria and USA also support the association between eclampsia and young maternal age $[23,24]$. The fullPIERS and miniPIERS models showed no association between maternal age and eclampsia, although eclampsia was rare $[25,26]$. These and our findings suggest that although advanced maternal age is a risk factor for pre-eclampsia, teenagers are at higher risk of eclampsia, even when referred to tertiary care. 
The association between high BMI and risk of pre-eclampsia is widely acknowledged [16-22]. The cohort design of our study does not allow robust conclusions on this association, although the data suggests raised BMI is a risk factor for pre-eclampsia. Our study demonstrates an association between low BMI and eclampsia. This is a novel finding and may be related to the association between eclampsia and young age. Existing literature, although limited, suggests that weight gain during pregnancy is more critical for teenage mothers than for older mothers $[27,28]$. In those teenage mothers with low BMI, it is plausible that the woman competes with the growing fetus for nutrients and, for this reason, these women may be more at risk of adverse outcomes.

Almost one fifth of women in our cohort had evidence of kidney injury. Systolic hypertension was strongly associated with risk of kidney injury and kidney injury was associated with a six times higher risk of maternal death. Proteinuria was less strongly associated with risk of kidney injury. $76.5 \%$ of women had $2+$ or more proteinuria. Although not as robust as quantitative assessment, this degree of proteinuria is likely to be an accurate reflection of kidney pathology. It was not possible to distinguish between acute and chronic renal impairment because few women had baseline creatinine values; however, previous studies have shown that the majority were likely to reflect acute kidney injury secondary to pre-eclampsia [2931]. Little exists in the literature on the long-term morbidity associated with pre-eclampsia-related acute kidney injury, particularly in LMICs where the burden is greatest. The importance of BP control in preventing acute kidney injury in a pre-eclamptic population requires further evaluation. Our data are consistent with the observation that chronic kidney disease affects almost twice as many women of childbearing age in low-income countries compared to high-income countries [29]. Obstetric acute kidney injury may be contributing to this discrepancy.

Our study showed a strong association between early gestational age at admission and risk of perinatal death. This association has been demonstrated with regard to stillbirth specifically, in a Haitain cohort of women with pre-eclampsia [32]. Early-onset disease is known to be severe and women may present too late for management to influence perinatal outcomes in our settings. The focus should be on community detection of pre-eclampsia and timely referral. Once in tertiary care, prolonging pregnancy may be a key intervention to improve perinatal outcomes but must be balanced with maternal morbidity. Given the high mortality antepartum and the low neonatal death rates, in lower-resourced settings, where monitoring during expectant management may be more challenging, risks of prematurity related to induction of labour to avoid stillbirth require further prospective evaluation.

\section{Interpretation}

Severe hypertension was common in this cohort, despite adequate access to appropriate antihypertensive treatment. This may, in part, be explained by the use of BP devices validated in pregnancy, including pre-eclampsia (rare in previous literature; most devices under-read in pre-eclampsia). Consequently, this study may have correctly identified hypertension that would have previously gone unrecognised [33]. The high incidence of severe hypertension may also represent under-treatment of severe hypertension by clinicians. As women are often asymptomatic and appear well, it is easy to underestimate their risk of complications. This study highlights the need to proactively control severe hypertension.

The incidence of pre-eclampsia complications, perinatal death and preterm delivery was much higher than reported in other low- and middle-income studies and despite access to tertiary care interventions. This may solely be a reflection of a cohort of women unwell enough to warrant tertiary care (and therefore, be at greatest risk of complications) or it could be explained by poor access to antenatal and postnatal care outside of facilities, socioeconomic factors resulting in delays in seeking care or pathophysiological factors inherent to the population.

Whether the association between teenage pregnancy and risk of eclampsia can be attributed to concomitant socioeconomic factors or biological features of young maternal age is contentious [34]. It has been explained by socioeconomic factors, with younger women attending antenatal care less frequently and seeking care less readily when symptomatic. Conversely, although the pathophysiological mechanisms are poorly understood [24], the association has been suggested to be explained by a biological immaturity, also related to brief paternal exposure, and lability of the central nervous system in younger women [15]. Teenage mothers are also more likely than older mothers to have inadequate weight gain during pregnancy and be nulliparous, which may result in inadequate immunological adaptation. These factors may accelerate the biological association between young age and eclampsia. Studies from USA, Canada and the Netherlands, as well as the most recent UK and Ireland Confidential Enquiries into Maternal Deaths 
(MBRACE) report, have shown that those of African ethnicity have increased risk of pre-eclampsia complications, including maternal death, despite living in high-income countries [21,35-42].

\section{CONCLUSIONS}

The results from this study could be used to inform management guidelines and policy. Delays in identifying the severity of hypertension will impact on timely referral and intervention and the outcomes. The association between teenage pregnancy and eclampsia risk highlights the importance of antenatal care, prompt referral and pregnancy education, including danger signs of imminent eclampsia, for young mothers.

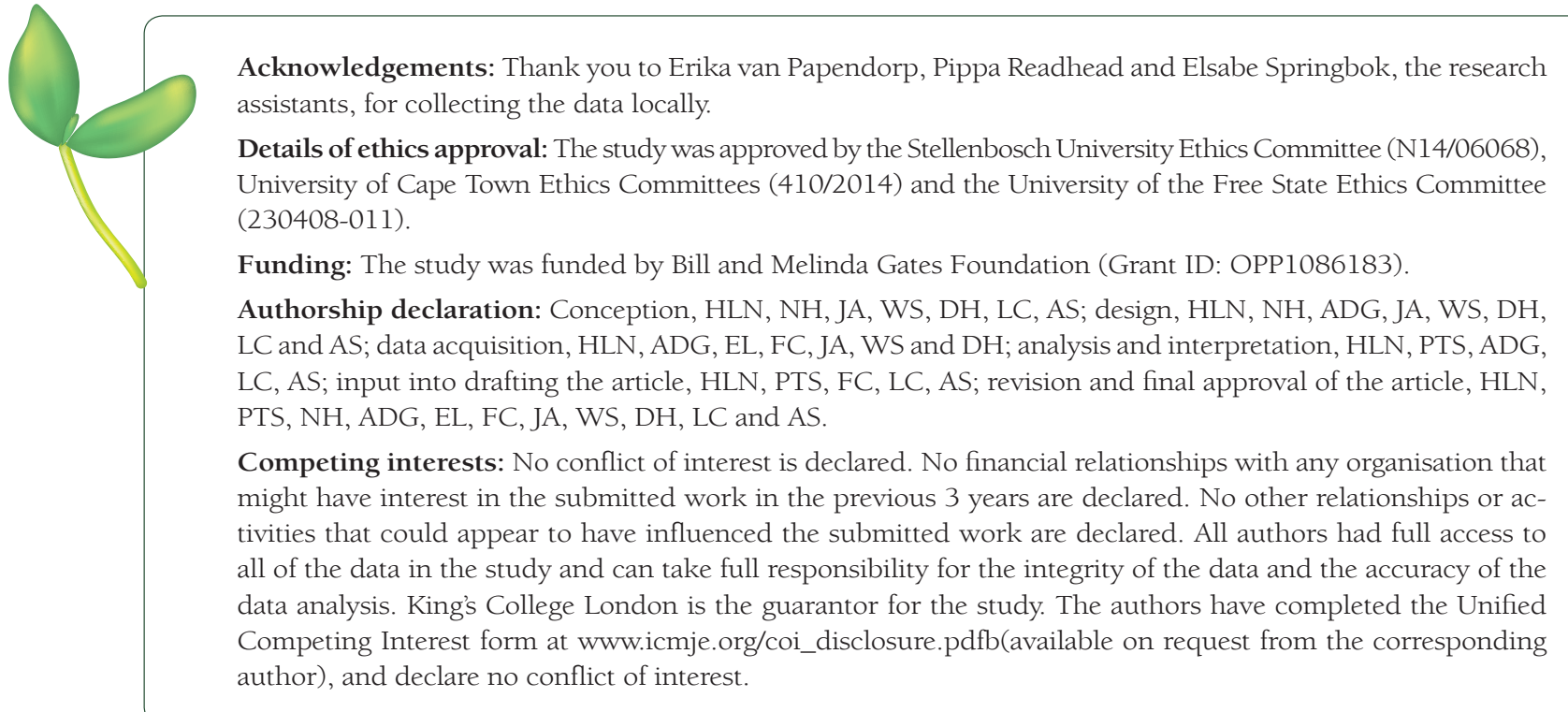

1 Kassebaum NJ, Bertozzi-Villa A, Coggeshall MS, Shackelford KA, Steiner C, Heuton KR, et al. Global, regional, and national levels and causes of maternal mortality during 1990-2013: a systematic analysis for the Global Burden of Disease Study 2013. Lancet. 2014;384:980-1004. Medline:24797575 doi:10.1016/S0140-6736(14)60696-6

2 Say L, Chou D, Gemmill A, Tunçalp Ö, Moller A-B, Daniels J, et al. Global causes of maternal death: a WHO systematic analysis. Lancet Glob Health. 2014;2:e323-33. Medline:25103301 doi:10.1016/S2214-109X(14)70227-X

3 von Dadelszen P, Sawchuck D, Hofmeyr GJ, Magee LA, Bracken H, Mathai M, et al. PRE-EMPT (PRE-eclampsia-Eclampsia Monitoring, Prevention and Treatment): A low and middle income country initiative to reduce the global burden of maternal, fetal and infant death and disease related to pre-eclampsia. Pregnancy Hypertens. 2013;3:199-202. Medline:26103796 doi:10.1016/j.preghy.2013.06.002

4 De Wet N. Pregnancy and death: An examination of pregnancy-related deaths among adolescents in South Africa. South African Journal of Child Health. 2016;10:151-5. doi:10.7196/SAJCH.2016.v10i3.978

5 Soma-Pillay P, Pattinson RC, Langa-Mlambo L, Nkosi BS, MacDonald AP. Maternal near miss and maternal death in the Pretoria Academic Complex, South Africa: A population-based study. S Afr Med J. 2015;105:578-83. Medline:26428756 doi:10.7196/SAMJnew.8038

6 Donnay F. Maternal survival in developing countries: what has been done, what can be achieved in the next decade. Int J Gynaecol Obstet. 2000;70:89-97. Medline:10884537 doi:10.1016/S0020-7292(00)00236-8

7 Alkema L, Chou D, Hogan D, Zhang S, Moller A-B, Gemmill A, et al. Global, regional, and national levels and trends in maternal mortality between 1990 and 2015, with scenario-based projections to 2030: a systematic analysis by the UN Maternal Mortality Estimation Inter-Agency Group. Lancet. 2016;387:462-74. Medline:26584737 doi:10.1016/S01406736(15)00838-7

8 Goldenberg RL, McClure EM, MacGuire ER, Kamath BD, Jobe AH. Lessons for low-income regions following the reduction in hypertension-related maternal mortality in high-income countries. Int J Gynaecol Obstet. 2011;113:91-5. Medline:21349517 doi:10.1016/j.ijgo.2011.01.002

9 Nathan HL, de Greeff A, Hezelgrave NL, Chappell LC, Shennan AH. An accurate semiautomated oscillometric blood pressure device for use in pregnancy (including pre-eclampsia) in a low-income and middle-income country population: the Microlife 3AS1-2. Blood Press Monit. 2015;20:52-5. Medline:25243711 doi:10.1097/MBP.0000000000000086 
10 Manktelow B, Smith L, Prunet C, Smith P, Boby T, Hyman-Taylor P, et al. MBRRACE-UK Perinatal Mortality Surveillance Report, UK Perinatal Deaths for Births from January to December 2015. Leicester: The Infant Mortality and Morbidity Studies, Department of Health Sciences, University of Leicester. 2017.

11 Intensive Care Society Report. Levels of Critical Care for Adult Patients. 2009.

12 The Magpie Trial Collaborative Group; Altman D, Carroli G, Duley L, Farrell B, Moodley J, Neilson J, et al. Do women with pre-eclampsia, and their babies, benefit from magnesium sulphate? The Magpie Trial: a randomised placebo-controlled trial. Lancet. 2002;359:1877-90. Medline:12057549 doi:10.1016/S0140-6736(02)08778-0

13 Martin JN Jr, Thigpen BD, Moore RC, Rose CH, Cushman J, May W. Stroke and severe preeclampsia and eclampsia: a paradigm shift focusing on systolic blood pressure. Obstet Gynecol. 2005;105:246-54. Medline:15684147 doi:10.1097/01. AOG.0000151116.84113.56

14 Magee LA, Abalos E, von Dadelszen P, Sibai B, Easterling T, Walkinshaw S. How to manage hypertension in pregnancy effectively. Br J Clin Pharmacol. 2011;72:394-401. Medline:21545480 doi:10.1111/j.1365-2125.2011.04002.x

15 Abalos E, Cuesta C, Carroli G, Qureshi Z, Widmer M, Vogel J, et al. Pre-eclampsia, eclampsia and adverse maternal and perinatal outcomes: a secondary analysis of the World Health Organization Multicountry Survey on Maternal and Newborn Health. BJOG. 2014;121:14-24. Medline:24641531 doi:10.1111/1471-0528.12629

16 Bodnar LM, Ness RB, Markovic N, Roberts JM. The risk of preeclampsia rises with increasing prepregnancy body mass index. Ann Epidemiol. 2005;15:475-82. Medline:16029839 doi:10.1016/j.annepidem.2004.12.008

17 Duckitt K, Harrington D. Risk factors for pre-eclampsia at antenatal booking: systematic review of controlled studies. BMJ. 2005;330:565. Medline:15743856 doi:10.1136/bmj.38380.674340.E0

18 Kuc S, Koster MP, Franx A, Schielen PC, Visser GH. Maternal characteristics, mean arterial pressure and serum markers in early prediction of preeclampsia. PLoS One. 2013;8:e63546. Medline:23717445 doi:10.1371/journal.pone.0063546

19 O'Brien TE, Ray JG, Chan W-S. Maternal body mass index and the risk of preeclampsia: a systematic overview. Epidemiology. 2003;14:368-74. Medline:12859040 doi:10.1097/01.EDE.0000059921.71494.D1

20 Conde-Agudelo A, Belizán JM. Risk factors for pre-eclampsia in a large cohort of Latin American and Caribbean women. BJOG. 2000;107:75-83. Medline:10645865 doi:10.1111/j.1471-0528.2000.tb11582.x

21 Sibai BM, Ewell M, Levine R, Klebanoff MA, Esterlitz J, Catalano P, et al. Risk factors associated with preeclampsia in healthy nulliparous women. Am J Obstet Gynecol. 1997;177:1003-10. Medline:9396883 doi:10.1016/S00029378(97)70004-8

22 Alves E, Azevedo A, Rodrigues T, Santos AC, Barros H. Impact of risk factors on hypertensive disorders in pregnancy, in primiparae and multiparae. Ann Hum Biol. 2013;40:377-84. Medline:23682598 doi:10.3109/03014460.2013.793390

23 El-Nafaty AU, Melah G, Massa A, Audu B, Nelda M. The analysis of eclamptic morbidity and mortality in the Specialist Hospital Gombe, Nigeria. J Obstet Gynaecol. 2004;24:142-7. Medline:14766449 doi:10.1080/01443610410001645415

24 Aliyu MH, Luke S, Kristensen S, Alio AP, Salihu HM. Joint effect of obesity and teenage pregnancy on the risk of preeclampsia: a population-based study. J Adolesc Health. 2010;46:77-82. Medline:20123261 doi:10.1016/j.jadohealth.2009.06.006

25 von Dadelszen P, Payne B, Li J, Ansermino JM, Pipkin FB, Côté A-M, et al. Prediction of adverse maternal outcomes in pre-eclampsia: development and validation of the fullPIERS model. Lancet. 2011;377:219-27. Medline:21185591 doi:10.1016/S0140-6736(10)61351-7

26 Payne BA, Hutcheon JA, Ansermino JM, Hall DR, Bhutta ZA, Bhutta SZ, et al. A risk prediction model for the assessment and triage of women with hypertensive disorders of pregnancy in low-resourced settings: the miniPIERS (Pre-eclampsia Integrated Estimate of RiSk) multi-country prospective cohort study. PLoS Med. 2014;11:e1001589. Medline:24465185 doi:10.1371/journal.pmed.1001589

27 Haiek L, Lederman SA. The relationship between maternal weight for height and term birth weight in teens and adult women. J Adolesc Health Care. 1989;10:16-22. Medline:2921184 doi:10.1016/0197-0070(89)90041-7

28 Hediger ML, Scholl TO, Belsky DH, Ances IG, Salmon RW. Patterns of weight gain in adolescent pregnancy: effects on birth weight and preterm delivery. Obstet Gynecol. 1989;74:6-12. Medline:2733943

29 Mills KT, Xu Y, Zhang W, Bundy JD, Chen C-S, Kelly TN, et al. A systematic analysis of worldwide population-based data on the global burden of chronic kidney disease in 2010. Kidney Int. 2015;88:950-7. Medline:26221752 doi:10.1038/ ki.2015.230

30 Prakash J, Niwas SS, Parekh A, Pandey LK, Sharatchandra L, Arora P, et al. Acute kidney injury in late pregnancy in developing countries. Ren Fail. 2010;32:309-13. Medline:20370445 doi:10.3109/08860221003606265

31 Randeree IG, Czarnocki A, Moodley J, Seedat Y, Naiker I. Acute renal failure in pregnancy in South Africa. Ren Fail. 1995;17:147-53. Medline:7644765 doi:10.3109/08860229509026251

32 Raghuraman N, March MI, Hacker MR, Modest AM, Wenger J, Narcisse R, et al. Adverse maternal and fetal outcomes and deaths related to preeclampsia and eclampsia in Haiti. Pregnancy Hypertens. 2014;4:279-86. Medline:26104817 doi:10.1016/j.preghy.2014.09.002

33 Gupta M, Shennan AH, Halligan A, Taylor DJ, Swiet M. Accuracy of oscillometric blood pressure monitoring in pregnancy and pre-eclampsia. Br J Obstet Gynaecol. 1997;104:350-5. Medline:9091015 doi:10.1111/j.1471-0528.1997.tb11467.x

34 Fraser AM, Brockert JE, Ward RH. Association of young maternal age with adverse reproductive outcomes. N Engl J Med. 1995;332:1113-7. Medline:7700283 doi:10.1056/NEJM199504273321701

35 Tanaka M, Jaamaa G, Kaiser M, Hills E, Soim A, Zhu M, et al. Racial disparity in hypertensive disorders of pregnancy in New York State: a 10-year longitudinal population-based study. Am J Public Health. 2007;97:163-70. Medline:17138931 doi:10.2105/AJPH.2005.068577 
36 Knuist M, Bonsel GJ, Zondervan HA, Treffers PE. Risk factors for preeclampsia in nulliparous women in distinct ethnic groups: a prospective cohort study. Obstet Gynecol. 1998;92:174-8. Medline:9699746

37 Goodwin AA, Mercer BM. Does maternal race or ethnicity affect the expression of severe preeclampsia? Am J Obstet Gynecol. 2005;193:973-8. Medline:16157096 doi:10.1016/j.ajog.2005.05.047

38 Eskenazi B, Fenster L, Sidney S. A multivariate analysis of risk factors for preeclampsia. JAMA. 1991;266:237-41. Medline:2056625 doi:10.1001/jama.1991.03470020063033

39 Urquia ML, Ying I, Glazier RH, Berger H, De Souza LR, Ray JG. Serious preeclampsia among different immigrant groups. J Obstet Gynaecol Can. 2012;34:348-52. Medline:22472334 doi:10.1016/S1701-2163(16)35215-X

40 Kung H-C, Hoyert DL, Xu J, Murphy SL. Deaths: final data for 2005. Natl Vital Stat Rep. 2008;56:1-120. Medline: 18512336

41 Zhang J, Meikle S, Trumble A. Severe maternal morbidity associated with hypertensive disorders in pregnancy in the United States. Hypertens Pregnancy. 2003;22:203-12. Medline:12909005 doi:10.1081/PRG-120021066

42 Knight M, Nair M, Tuffnell D, Kenyon S, Shakespeare J, Brocklehurst P, et al. Saving Lives, Improving Mothers' Care Surveillance of maternal deaths in the UK 2012-14 and lessons learned to inform maternity care from the UK and Ireland Confidential Enquiries into Maternal Deaths and Morbidity 2009-14. Oxford: National Perinatal Epidemiology Unit, University of Oxford. 2016. 